chairman and member of the group medical executive committee-is a typical divisional member. Is a more active role in management going to be required of such doctors to make the resources of the N.H.S. look after the health of the individual adequately?

Perhaps understandably, the second Cogwheel report ${ }^{5}$ does not say much about the attitudes of individuals to these subjects.

\section{References}

1 First Report of the Foint Working Party on the Organization of Medical Work in Hospitals. London, H.M.S.O., 1967.

2 British Medical fournal, 1972, 4, 36.

3 Report of the Working Party on Medical Administration. London, H.M.S.O., 1972 .

National Health Service Reorganization: England. London, H.M.S.O., 1972.

5 Second Report of the Joint Working Party on the Organization of Medical Work in Hospitals. London, H.M.S.O., 1972.

\title{
Medical Engineering
}

\section{Biomedical Engineering at King's}

\author{
FROM A SPECIAL CORRESPONDENT
}

British Medical fournal, 1972, 4, 604-605

At present there are only a handful of medical engineering units in Britain, but even so it might seem fanciful to suggest that they have all developed in a similar way. If there is a common pattern this seems to be divisible into three main stages. To start with, a doctor reaches a stage in his research when he realizes that he needs help from non-medical scientists to help him solve his problems; he then sets about convincing other people that a multidisciplinary team is both desirable and necessary. Next, he spends a lot of time obtaining the right staff, building, equipment-and, in particular, sufficient money-to get a unit started. The third stage often the easiest; the actual research work itself, even though usually other problems or research projects are thrown up by it results. Finally, the unit may become so successful that other hospital departments seek its help. It is often just at this stage that the original grants run out, the whole team is plunged into uncertainty about its future, and much valuable time is spent in hunting for money.

Even if it is not a general rule, this pattern certainly applies to the Biomedical Engineering Unit at King's College Hospital in London. This arose out of the enthusiasm of Mr. L. T. Cotton, a consultant surgeon at the hospital whose interests have always been in the vascular field. He was dissatisfied with the then current methods of monitoring blood flow, and became concerned to find accurate answers to three main questions. How much is blood flow slowed in various conditions? How can this slowing be measured-before operation, during it, and afterwards? And how can slowing of flow be prevented, particularly to stop the development of deep vein thrombosis? To try to solve these and other problems he first established a link with the University of Surrey. But since most of the research would inevitably be patient-orientated it soon became evident that a unit would have to be established at the hospital itself. Here the connexion with Surrey University proved invaluable: the unit's research workers in the various engineering disciplines have all undertaken postgraduate studies in biomechanics at Surrey and while at King's are supervised for their Ph.D.'s by Professor J. M. Zarek, who heads Surrey's Mechanical Engineering Department and who shares a joint directorship of the department at King's. Moreover, postgraduates on the M.Sc. course at Surrey come to King's for a course on clinical aspects of biomedical engineering.
Having obtained a generous grant from the Wates Foundation, the unit was started at King's in 1967; subsequently, other funds were given by the British Heart Foundation, and this year it obtained $£ 14,000$ worth of machine tools under the Government's new scheme to help the industry, and $£ 5,000$ from the Beaverbrook Foundation. In 1971 the unit obtained the space it needed; most of it moved into the old pathology department at Dulwich Hospital nearby, though it still retains one room in the research corridor at King's itself, which forms a base for both clinical work and research carried out in the animal house. Mr. Cotton is the unit's director at King's, and there are six other members of the team: another surgeon, four professional engineers, and a secretary. Nevertheless, though the senior engineer now has honorary lectureship status, not a single one of the posts is established. Moreover, there has never been enough money to pay for a technician to service the machines or to do the routine work, all of which has always been done by the graduates themselves. With the Wates grant now drawing to an end the future is a constant worry-"all we really need is a little stability and some technical assistance," as one team member said quietly when asked what more they wanted.

\section{Work in Progress}

One major result of the team's work has been the development of a cheap, simple method of prophylaxis for deep vein thrombosis. The basis of this is intermittent compression of the legs throughout any surgical operation using a plastic bag supplied by a cylinder of compressed air, controlled by a small box with only simple pneumatic valves (Fig. 1). In practice, the new device is easy to use, and needs no attention during operation. It has been found to decrease the incidence of deep vein thrombosis by $80 \%$ for six days after surgery-in other words, to give rather better results than prophylaxis using techniques of passive exercise, which the team had originally worked on.

Another important research project has been to develop an accurate flowmeter using the principle of thermal dilution. Basically the device consists of a double-barrelled, fine nylon tube which is passed into the blood vessel. Saline at room temperature is injected through the inner channel and enters the blood stream a short distance away from the end of the tube. The probe contains a thermistor which measures the 
FIG. 1-Device for prevein thrombosis by preoperative intermittent compression of the legs. venting postoperative deep

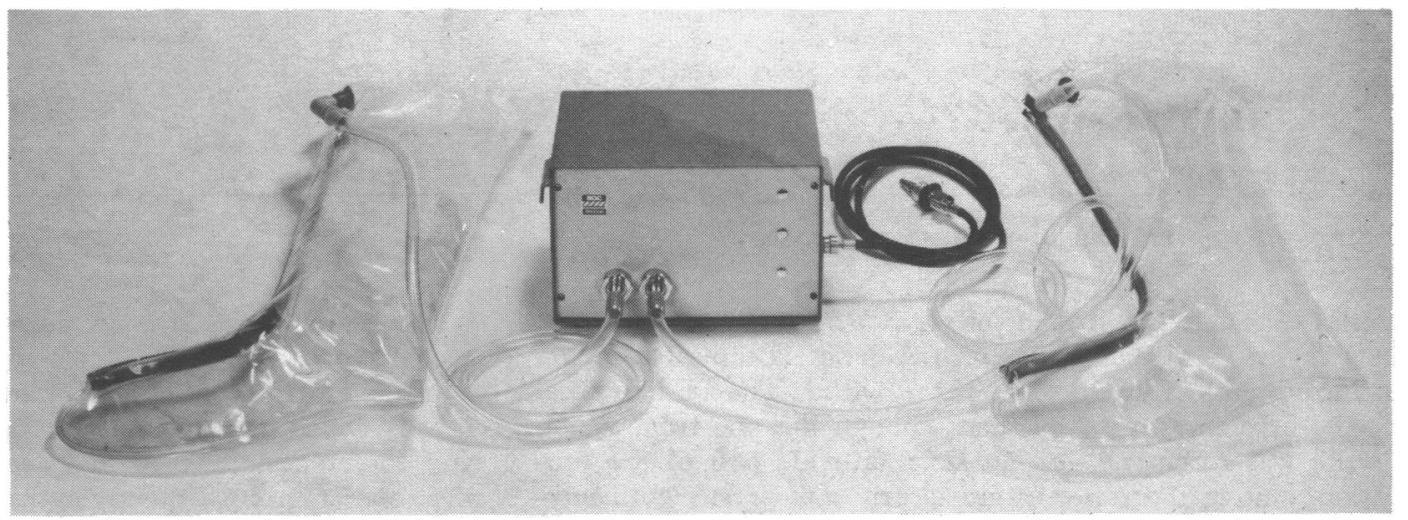

temperature of the blood prior to saline injection and the temperature of the mixture of blood and saline during injection. From these temperatures the flow rate can be instantly computed. Nevertheless, as well as knowing about the amount of flow, the surgeon also wants to know about its pressure. It may be possible to evaluate this by measuring the amount of light reflected from a diaphragm on the end of a fibreoptic probe, again inserted as a tube into a blood vessel. After tests and calibration in animals the electromagnetic flowmeter is now supplementing arteriography in patients in the diagnosis of localized vascular disease and during operation to monitor the results of surgery. The results have been used in surgical procedures on the profunda femoris artery in deciding which type of operation to perform: thus a flow of over $100 \mathrm{ml}$ per minute is an indication for inserting a saphenous-vein bypass graft, while one of under that figure suggests that an extensive profunda femoris angioplasty should be performed. The use of the flowmeter during operation has also enabled the team to reduce the number of failures in endarterectomy of the carotid, aorta, and iliac arteries.

Research into fibreoptics is aiming principally to allow inspection of the lining of the blood vessels, which can be done fairly readily once the blood flow has been temporarily stopped by inflating a balloon in the vessel lumen. This procedure could have several important uses: destroying the valves under direct vision when preparing a saphenous-vein graft; assessing the end result after operation on a blood vessel-such as the adequacy of the rebore after endarterectomy, the absence of further blood clots after thrombectomy, or the quality of an anastomosis. Relatively

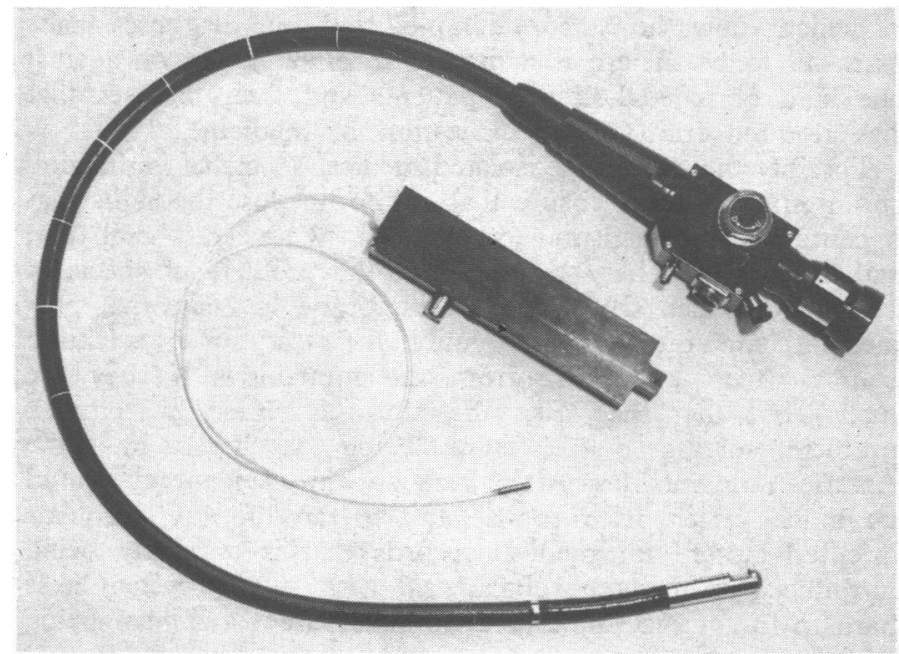

FIG. 2-A prototype fine-calibre fibrecoptic endoscope surrounded by a conventional fibreoptic gastroscope. large-sized fibrescopes have now been available for some time, but at King's work has concentrated on developing fine calibre ones-that is, having a diameter of only $3 \mathrm{~mm}$ (Fig. 2). The instrument so far developed, in collaboration with the Rank Organization and the Department of Optics at Reading University, has cost only about $£ 200$-about onesixth of the price of the commercially available models. Other possible future uses of this extremely fine endoscope might include examination of the bile duct, uneter, and kidneys, intervertebral discs, and the interior of joints.

\section{Outlook Uncertain}

I asked the team what lessons they had learnt during the unit's existence. They emphasized how important it was to get just the right number of people in the team. This meant that there was at least one expert in each major discipline to advise on a problem that might arise out of another expert's projects-but that the unit did not become too big for its members to lose contact with one another. Another rule they supported was to stick to a few major projects and not get sidetracked, however potentially tempting any new piece of research might be. This might mean hardening one's heart when asked for major help by another unit in the hospital, but it was necessary if any major developments were to be made. But over the whole unit, of course, hangs the perpetual questionmark of its future: the present grant runs out in 1973. The inability to plan future developments must inevitably unsettle the staff, while the' unit's director spends valuable time canvassing widely for funds. King's College Hospital is not one of the better endowed teaching hospitals, and the unit has been told that even after the proposed merger with Guy's Hospital there will be no university money available for it until at least 1974. Yet it would seem folly to disband such a promising unit for the want of a relatively small sum- $£ 16,000$ a year at present, and just over three times this amount for full development. For one thing, once dispersed, a combination of such skills would be difficult to achieve again. For another, as the 47 articles published in the last five years show, the unit's projects have fulfilled the Rothschild so-called "customer-consumer" principle: routine use of intermittent compression of the leg might prevent one of the commonest causes of death in this country, pulmonary embolism; use of the flowmeter for monitoring arterial blood carried out, reducing the amputation rate from $33 \%$ to $10 \%$; and there are real prospects of developing a simple instrument for inspecting blood vessels in the outpatient department as well as the operating theatre. How many other research units can offer the prospect of such potentially exciting products? flow has enabled more precise arterial reconstruction to be 